\title{
The role of increased gonotrophic cycles in the establishment of Wolbachia in Anopheles populations
}

Lauren M. Childs

Virginia Polytechnic Institute and State University, Ichilds@vt.edu

Ryan Hughes

Julie Blackwood

Follow this and additional works at: https://scholarscompass.vcu.edu/bamm

Part of the Life Sciences Commons, Medicine and Health Sciences Commons, and the Physical Sciences and Mathematics Commons

https://scholarscompass.vcu.edu/bamm/2020/talk/30

This Event is brought to you for free and open access by the Dept. of Mathematics and Applied Mathematics at VCU Scholars Compass. It has been accepted for inclusion in Biology and Medicine Through Mathematics Conference by an authorized administrator of VCU Scholars Compass. For more information, please contact libcompass@vcu.edu. 
Wolbachia, a bacterium that infects insect populations, has been examined extensively in Drosophila populations and, in recent years, has garnered significant attention for its potential to reduce the spread of dengue in the Aedes mosquito population. Similar applications to Anopheles mosquitoes for the reduction of malaria have not been as thoroughly studied, as Anopheles were previously thought to be devoid of Wolbachia infection. The recent discovery, however, of Wolbachia in two separate wild Anopheles populations suggests further study is needed. We develop and analyze an ordinary differential equation model of Wolbachia infection in Anopheles mosquitoes, which demonstrate different reproductive phenotypes than Aedes mosquitoes when infected with Wolbachia. In particular, they do not show the hallmark cytoplasmic incompatibility phenotype - absence of viable offspring when infected males mate with uninfected females - or other standard sex-biasing phenotypes. Instead, evidence of increased speed of gonotrophic cycles by Wolbachia-infected females has been reported. We show that the ability for Wolbachia to invade for a basic reproductive number less than one $\mathrm{R}_{\text {pop }}<1$ found in other models, is significantly diminished here. However, the invasion threshold below $R_{\text {pop }}<1$ can be partially recovered with the increased speed of laying eggs, as incorporated through gonotrophic cycles. Our results highlight the need for further experimental and theoretical work if Wolbachia is to be considered as a form of malaria control. 